\title{
Effective communication of Prognosis at the Cochin Cancer Research Centre
}

\author{
P K Prem Ravi Varma* \\ Department of Medical Oncology, Ernakulam Government Medical College Compound, India
}

Submission: February 04, 2020; Published: February 20, 2020

*Correspondence Author: P K Prem Ravi Varma, Head of Department, Department of Medical Oncology, Cochin Cancer Research Centre, Government Medical College Campus, ER.515/06, HMT Colony, North Kalamassery, Kochi, Kerala State 683503, India

\begin{abstract}
One of the most important skills in medicine is communication. It lies at the heart of the doctor-patient relationship and is particularly important when one has been diagnosed with a potentially life-threatening condition. Words are powerful and too often can be interpreted in ways not intended. This is a discussion on the concept of shared decision making, and how it can be used when there is uncertainty in what treatments may (or may not) accomplish. Finally, the discussion on the skills that constitute a toolkit for communication, which hopefully can be tailored to meet the variable needs of those we are caring for and by doing so, can be of help to clinicians in their own practices. In the era of personalized medicine, treatments may become more complex, and more options may be available. A hope to encourage providers to welcome patients as active participants in their care by sharing information, requesting their input, and by engaging them in important processes such as advance care planning-to ensure their needs and wishes are respected in the present and for whatever may come in the future.

Clinical education has made significant progress addressing the challenges that clinicians face when communicating with patients and their loved ones [1]. Certain specific skills have been identified that can help us when giving bad news or discussing therapeutic options or endof-life care [2]. These conversations can be organized and broken down into steps, much as is done with medical procedures [3,4]. A second development has been the appreciation for empathy and the benefit patients derive from feeling that their clinician cares about their concerns and their experience [5]. As more information about cancer survival becomes available, oncologists must face ways to discuss this information with patients. The article reviews some of the key evidence about what patients want to hear and outlines an approach for oncologists to use in talking to patients and their families.
\end{abstract}

\section{Introduction}

The amount of information an oncologist should give to a patient with a bad prognosis is a common dilemma. Many accounts written by patients living with cancer emphasize the need for hope that they will beat the odds, and many oncologists worry that talking about statistics could damage a patient's hope. However, most oncologists have had personal experiences with patients who have avoided talking about their prognosis. This article reviews how oncologists can handle this critical topic.

At the Cochin Cancer Research Centre interviews with patients indicate that patients are interested in prognostic information. In a survey of 371 patients with cancer at the Medical Oncology outpatient clinic, 99\% indicated that they wished to have "all information "about their cancer. A systematic review found that patients or relatives who want more detailed information are younger and more educated and believe that they have less time to live. However, studies that asked more detailed queries about prognosis find more variability in what patients want [1]. In a study of 126 patients with metastatic cancer in Australia, more than $95 \%$ of patients wanted information about treatment options, $85 \%$ wanted to know the longest survival time with treatment, $59 \%$ wanted to discuss survival when first diagnosed, and $38 \%$ wanted to negotiate when survival would be discussed. This study found that lower depression levels were significantly associated with patients who never wanted to discuss expected survival [2]. Patients tend to want less information as the illness progresses, whereas their caregivers want more information [3].

A minority of patients are cautious about the kind of prognostic information they want. In the previously mentioned Australian survey, $5.4 \%$ of patients said they wanted "only good news." Some of this variability is related to coping style, although this notion has not been studied specifically. Another source of variability that has been studied is cultural diversity. In a survey of 350 senior citizens i.e., patients with cancer at the Medical Oncology outpatient clinic at the Cochin Cancer Research Centre, $87 \%$ of native malayalee population believed that a patient should be informed of a diagnosis of metastatic cancer, compared with 


\section{Cancer Therapy \& Oncology International Journal}

only $35 \%$ of migrants from different parts of the country who believed the same.

A systematic review that included cancer and other lifelimiting diagnosis concluded that existing studies show a large discrepancy between the amount of prognostic information given as reported by patients and caregivers compared with health professionals [4]. The uncertainty and difficulty of making accurate predictions about survival still exist. In a prospective cohort study of 313 patients who underwent autologous and allogeneic stem cell transplantation, physicians tended to overestimate survival, especially for patients with poor prognosis, whereas patient expectations remained high regardless of disease stage [5]. At the other end of the illness trajectory, physicians are similarly inaccurate. In a study of patients who were entering hospice, only $20 \%$ of physicians' predictions were accurate, and $63 \%$ were overoptimistic [6].

Physicians sometimes provide information selectively because they are concerned about allowing patients to preserve hope. Physicians who treat life-limited cancers tend to be optimistic, and this bias is not limited to physician speciality [6]. In one study of patients who were referred to hospice, oncologists reported that they would not provide any survival stimate $22 \%$ of the time , their own survival estimate $37 \%$ of the time and a different survival estimate (usually optimistic) $40 \%$ of the time [7]. In a survey of 194 parents of children with cancer, parents were asked about the type of prognostic information they had received and about their hope. No evidence was found that prognostic disclosure made parents less hopeful. Physicians can support hope even when prognosis is poor [8]. Parents who found the prognostic information upsetting were no less likely to confirm that knowing the prognosis was important and that it helped in the desision-making process [9]. In a different longitudinal qualitative study of patients and physicians with advanced cancer, patients also reported that how physicians relayed information supported hope in a variety of ways, not strictly limited to survival estimates [10].

Common Strategies for Dealing with Prognosis: Realism, Optimism, and Avoidance

Realism, optimism, and avoidance are the most common strategies physicians use in discussing prognosis. None of these strategies are completely satisfactory, but each has useful features. Realism helps patients and physicians make sound decisions. Both bioethical reasoning and epirical evidence support the importance of accurate patient understanding of a prognosis; however, patients also report that realistic prognostic discussions are blunt and sometimes brutal. A physician who presents a prognosis realistically, but without structuring the conversation before the information is given or responding empathetically afterward, can be perceived as uncaring. Moreover, a subset of patients, particularly those with advanced, metastatic disease, does not want complete information about their prognosis. Giving patients in that subset realistic information may cause psychologic harm, although there are no known studies that address this question.

Optimism can be useful in supporting a patient's hopes because many patients report that they want a doctor who is hopeful $[11,12]$. In discussions about prognosis, however, physicians who deliberately exaggerate or overemphasize optimistic information may risk losing the trust of patients who later discover that the information they received was only partially true [13]. Patients who are overly optimistic about their chances of survival are more likely to choose life-sustaining therapies in the last 6 months of life [14], often when these therapies are least effective. These patients may lose opportunities to plan their lives to maximize their remaining time, plan their financial affairs, and work toward life closure [15].

A third strategy is to avoid prognostication altogether, often by emphasizing individual differences, unpredictability of disease course, or exceptional outliers. Collusion is a variation of this strategy, in which physicians avoid discussing prognosis altogether by creating a tacit understanding that neither patient nor physician will bring up the topic [16,17]. Avoidance is based on reasonable concerns. First, physicians realize that they are often inaccurate when predicting survival for a patient [6]. Second, physicians worry that discussing survival communicates a subtle psychologic message that a patient will die [11]. Third, physicians find that some patients do not want prognostic information. Finally, physicians find that bad news often distresses patients [18]. Yet physicians who avoid prognostication may seem evasive and, consequently, untrustworthy, especially when studies indicate that many patients want to talk about life expectancy [19]. Although discussing a prognosis can be stressful, unpleasant news is not an enough reason to avoid it.

\section{A Better Alternative: How Much Patients want to Know}

The proposed approach for discussing prognosis is based on negotiation and patient-centred communication as well as the available research on what patients want to know $[20,21]$. Discussing prognosis is more complex than other communication, such as relaying bad news, because it requires a synthesis of communication skills and biomedical content knowledge [22,23]. This approach assumes that physicians are comfortable with fundamental communication skills, such as detecting emotions, responding empathetically, and eliciting patient understanding $[24,25]$. The approach also assumes that the physician is prepared to discuss relevant biomedical literature that describes prognosis $[26,27]$.

\section{A Roadmap for Conversations: The Opening Question}

Because studies show that most patients want to discuss their prognosis, physicians should ask explicitly how much patients want to know. A physician could even normalize a range of patient interest by stating that "although some patients prefer details, 


\section{Cancer Therapy \& Oncology International Journal}

some want the big picture", and others prefer that the physician to talk to their family. Patients who want explicit information are more likely to try to understand and retain information they want. Physicians can negotiate information by establishing a patient's needs and proposing ways to meet those needs. These negotiations enable patients to indicate their interests and readiness to hear information. The physician can explain that there are a few ways to answer a patient's question, including providing statistics or mentioning the worst-case scenario and the best-case scenario [28].

At this point, the physician will know that the patient is interested in hearing the information and should be clear about the type of information the patient wants. Many patients may not understand how to use statistical information, such as median intervals, and a substantial number of patients may have difficulty comprehending and retaining numerical data (i.e., explicitly name both the chance of cure and the chance of relapse and discuss absolute survival benefits, rather than relative risk reduction). The physician should acknowledge the patient's and families' reactions because they are likely to respond emotionally, particularly if it is bad news. Physicians often withdraw from these emotional reactions, although verbal acknowledgement of the reaction can facilitate a deeper conversation. It is best to use empathetic statements that demonstrate that the physician perceives the emotion, understands the patient's situation, respects the emotion, supports the patient, or is willing to explore the reaction [29]. Although an empathetic silence can be powerful, it can leave patients unsure as to whether they can talk to their physician about their emotional reactions [30]. Patients and family members often misinterpret complex medical information because they hear either the bad or good aspects of the message; therefore, physicians should make sure the patient heard the intended message.

Some patients will indicate that they do not want to discuss prognostic information, which may leave the physician in an awkward place. The physician will want to respect the patient's wishes but may be worried that hopes rather than facts may cloud patient decision making [31]. Two general principles that are useful in these situations include understanding why a patient doesn't want to know and realizing that decision making does not always require that the patient understand detailed prognostic information. Confronting patients with information they do not want is a waste of time and can be counterproductive because it makes patients feel that the physician is not "on their side."

Although many physicians simply step back after hearing that a patient does not want to talk about prognosis, understanding the patient's view can provide insight into reasoning and coping [32]. The reason the patient doesn't want to talk can be a useful and trust-building step. A patient may reveal that he or she is sad and worried that discussion will deepen sorrow, is concerned about how the information will affect a spouse, or wants a family member to make the medical decisions - all issues with practical consequences for the physician [33]. As previously indicated, physicians should explicitly acknowledge the patient's concern, which demonstrates that the physician understands the patient's reasoning and emotions. In some situations, physicians may feel that a patient has a misunderstanding of the prognosis, which may contribute to poor decision making. Physicians may consider negotiating for limited disclosure or clarifying whether another person (i.e., designated proxy) should receive the information [34]. If the physician cannot identify a compelling reason to discuss prognostic information, then he or she should follow the patient's wishes. In this case, the physician should ask for permission to revisit the topic. The patient may want another person to receive the information; although some patients do not want details regarding their prognosis, another family member may want the information (with the patient's permission) and, in our experience at the Cochin Cancer Research Centre, may use the information to help families avoid decisions based on unrealistic expectations.

If the physician believes there is compelling reason for discussing prognostic information and the patient does not identify another person with whom to discuss the information, a physician may negotiate for limited disclosure by informing the patient that the prognosis is important for discussion and that prognostic information may influence the patient's decision making. A substantial number of patients may have mixed feelings about knowing their prognosis. This can be frustrating for physicians because patients may be open to receiving information, but they may want the opposite of what the physician proposes. More subtle ambivalence involves a patient who indicates that he or she wants to talk about the prognosis, but simultaneously gives other signals, like changing the topic or looking away. The principle for dealing with ambivalence is to discuss it explicitly and allow patients to talk about the pros and cons. Physicians should acknowledge that the patient has good reasons for wanting or not wanting the information. This demonstrates a physician's understanding of the patient's individual complexity and prevents a premature end to the discussion [35]. Rather than trying to push the patient into either category, the physician may ask the patient to explain both sides of their dilemma. As the patient discusses these feelings, a decision may become clear. A great deal of ambivalence around discussing prognostic information is based on tension between wanting to know the information for pragmatic reasons and being fearful of the emotional effects on the self and loved ones. This tension is not something that a simple communication technique can relieve. Physicians should demonstrate that they understand the difficulty of the patient's situation. The physician should empathize with the patient's difficult situation, which provides support, and wait for the patient to initiate the next step in determining how much information is needed. Empathy remains the single most useful communication practice. Although empathy enables physicians to address most patients with ambivalence, physicians also can outline the options for discussion (which are usually different 


\section{Cancer Therapy \& Oncology International Journal}

levels of disclosure) and the ways in which these options will meet the patient's concerns. Making the consequences more concrete from the patient's perspective may enable the patient to come to a decision. In many instances, patients will want to think about these options in private.

\section{Assessing Communication Effectiveness}

Physicians often rely on the "feel" of a conversation to know whether they have communicated effectively, yet studies indicate that self-evaluation is not always accurate. A more effective way to judge the effectiveness of a discussion about prognosis is to ask the patient if they feel that the appropriate information was relayed. This is meant to focus on the process of the conversation rather than the accuracy of information delivery. A successful prognosis discussion involves engaging the patient in a process of growing understanding of the situation, understanding evolving information needs, and providing the information in a way that the patient can absorb.

The American Society of Clinical Oncology (ASCO) communication guideline is grounded in the relationship with the patient, which we at the Cochin Cancer Research Centre view as the cornerstone of comprehensive health care. Relationship-centered care involves a greater focus on listening skills in the service of understanding who our patients are, what their experience of illness has been, and what matters to them. It involves prioritizing the establishment of trust and a willingness to partner with patients and personalize their care by being responsive to their individuality.

In September 2017, ASCO published its first ever guideline on patient-clinician communication. Better communication results in better medical outcomes, better patient experience, and improved patient safety. And yet communication skills have often been regarded as something that one can simply "pick up" through observation and practice. Sometimes, communication skills have been confused with basic relational skills, as if being good in social conversations sufficed for clinicians discussing complex medical issues and emotionally fraught diagnoses with patients and their loved ones.

The ASCO communication guideline provides specific recommendations for accomplishing these goals. One of the greatest challenge's oncologists face is to present accurate information while sustaining and supporting hope in the face of a devastating diagnosis. It can be tempting to provide false reassurance. We can do a better job of sustaining hope honestly if we know who our patients are as individuals, if we have developed a trusting relationship, and if their experience with us confirms to them that we care. Communication represents a large portion of our work caring for patients with cancer and our skill at communicating has a substantial impact on patient experience and patient outcomes. Our effectiveness as communicators also has a large impact on us. When we communicate better, our relationships improve. Our days are better when we can establish strong, trusting and resilient relationships; when we feel that we have meaningful and rewarding connections with the people around us.

Areas Addressed in ASCO Patient-Clinician Communication Guideline

i. Core Communication Skills

ii. Discussing Goals of Care and Prognosis

iii. Discussing Treatment Options and Clinical Trials

iv. Discussing End-of-Life Care

v. Using Communication to Facilitate Family Involvement in Care

vi. Communicating Effectively When There Are Barriers to Communication

vii. Discussing Cost of Care

viii. Meeting the Needs of Underserved Populations

ix. Clinician Training in Communication Skills

\section{References}

1. Tulsky JA, Beach MC, Butow PN, Hickman SE, Mack JW, et al. (2017) A Research Agenda for Communication Between Health Care Professionals and Patients Living with Serious Illness. JAMA Intern Med 177(9): 1361-1366.

2. Baile WF, Buckman R, Lenzi R, Glober G, Beale EA, et al. (2000) SPIKES-A six-step protocol for delivering bad news: application to the patient with cancer. Oncologist 5(4): 302-311.

3. Childers JW, Back AL, Tulsky JA, Arnold RM, et al. (2017) REMAP: A Framework for Goals of Care Conversations. J Oncol Pract 13(10): e844-e850.

4. Gerretsen P, Myers J (2008) The physician: a secure base. J Clin Oncol 26(32): 5294-5296.

5. Jenkins V, Fallowfield L, Saul J (2001) Information needs of patients with cancer: results from a large study in Uk cancer centres. Br J Cancer 84(1): 48-51.

6. Hagerty RG, Butow PN, Ellis PA, Lobb EA, Pendlebury S, et al. (2004) Cancer patient preferences for communication of prognosis in the metastatic setting. J Clin Oncol 22(9): 1721-1730.

7. Parker SM, Clayton JM, Hancock K, Walder S, Butow PN, et al. (2007) A systematic review of prognostic/ end-of-life communication with adults in the advanced stages of a life-limiting illness: patient/ caregiver preferences for the content, style, and timing of information. J Pain Symptom Manage 34(1): 81-93.

8. Blackhall LJ, Murphy ST, Frank G, Michel V, Azen S, et al. (1995) Ethnicity and attitudes toward patient autonomy. JAMA 274(10): 820-825.

9. Hancock K, Clayton JM, Parker SM, Walder S, Butow PN, et al. (2007) Discrepant perceptions about end-of-life communication: a systematic review. J Pain Symptom Manage 34(2): 190-200.

10. Lee SJ, Fairclough D, Antin JH, Weeks JC (2001) Discrepancies between patient and physician estimates for the success of stem cell transplantation. JAMA 285(8): 1034-1038.

11. Christakis NA, Lamont EB (2000) Extent and determinants of errorin doctors' prognoses in terminally ill patients: prospective cohort study. Bmj 320(7233): 469-472. 


\section{Cancer Therapy \& Oncology International Journal}

12. Lamont EB, Christakis NA (2001) Prognostic disclosure to patients with cancer near the end of life. Ann Intern Med 134(12): 1096-1105.

13. Mack JW, Wolfe J, Cook EF, Grier HE, Cleary PD, et al. (2007) Hope and prognostic disclosure. J Clin Oncol 25(35): 5636-5642.

14. Mack JW, Wolfe J, Grier HE, Cleary PD, Weeks JC, et al. (2006) Communication about prognosis between parents and physicians of children with cancer: parent preferences and the impact of prognostic information. J Clin Oncol 24(33): 5265-5270.

15. Curtis JR, Engelberg RA, young PJ, Vig LK, Reinke LF, et al. (2007) An approach to understanding the interaction of hope and desire for explicit prognostic information among individuals with severe COPD or advanced cancer. J Palliat Med 11(4): 610-620.

16. Delvecchio Good MJ, Good BJ, Schaffer C, Lind SE (1990) American Oncology and the discourse on hope. Cult Med Psychiatry 14(1): 59-79.

17. Clayton JM, Butow PN, Arnold RM, Tattersall MH, et al. (2005) Fostering coping and nurturing hope when discussing the future with terminally ill cancer patients and their caregivers. Cancer 103(9): 1965-1975.

18. . Fallowfield LJ, Jenkins VA, Beveridge HA (2002) Truth may hurt but deceit hurts more: communication in palliative care. Palliat Med 16(4): 297-303.

19. Weeks JC, Cook EF, O’Day SJ, Peterson LM, Wenger N, et al. (1998) Relationship between cancer patients' predictions of prognosis and their treatment preferences. JAMA 279: 1709-1714.

20. Quill TE (2000) Perspectives on care at the close of life. Initiating endof-life discussions with seriously ill patients: addressing the "elephant in the room. JAMA 284(19): 2502-2507.

21. The AM, Hak T, Koeter G, van der Wal G, (2000) Collusion in doctorpatient communication about imminent death: an ethnographic study. Bmj 321(7273): 1376-1381.

22. Helft PR (2005) Necessary collusion: prognostic communication with advanced cancer patients. J Clin Oncol 23(13): 3146-3150.

23. Schofield PE, Butow PN, Thompson JF, Tattersall MH, Beeney LJ, et al. (2003) Psychological responses of patients receiving a diagnosis of cancer. Ann Oncol 14(1): 48-56.
24. Clayton JM, Butow PN, Tattersall MH ( 2005) When and how to initiate discussion about prognosis and end of life issues with terminally ill patients . J Pain Symptom Manage 30(2): 132-144.

25. Back AL, Arnold RM (2006) Discussing prognosis: "how much do you want to know?": talking to patients who do not want information or who are ambivalent. J Clin Oncol 24(25): 4214-4217.

26. Back AL, Arnold RM (2006) Discussing prognosis: "how much do you want to know?": talking to patients who are prepared for explicit information. J Clin Oncol 24(25): 4209-4213.

27. Stone D, Patton B, Heen S (2000) Difficult conversations: How to Discuss What Matters Most. Penguin Putnam, New York, USA.

28. Back AL, Arnold RM (2005) Dealing with conflict in caring for the severely ill: "it was just out of the question. JAMA 293(11): 1374-1381.

29. Kurtz SM, Silverman J, Draper J (2005) Teaching and Learning Communication Skills in Medicine. Health Expect, Radcliffe Publications, London, 8(4): 363-365.

30. Back AL, Arnold RM, Baile WF, Tulsky JA, Fryer-Edwards K (2005) Approaching difficult communication tasks in oncology. CA Cancer J Clin 55(3): 164-177.

31. Lipkin M, Putnam SM, Lazare A (1995) The Medical Interview: Clinical Care, Education, and Research. Springer-Verlag, New York, USA.

32. Epstein RM,Alper BS, Quill TE (2004) Communicating evidence for participatory decision making. JAMA 291(19): 2359-2366.

33. Groopman JE (2005) A strategy for hope: a commentary on necessary collusion. J Clin Oncol 23: 3151-3152.

34. Studts JL, Abell TD, Roetzer LM, Albers AN, McMasters KM, et al. (2005) Preferences for different methods of communicating information regarding adjuvant chemotherapy for breast cancer. Psychooncology 14(8): 647-160.

35. Epstein RM (1999) Mindful practice. JAMA 282(9): 833-839.

\section{Your next submission with Juniper Publishers will reach you the below assets}

- Quality Editorial service

- Swift Peer Review

- Reprints availability

- E-prints Service

- Manuscript Podcast for convenient understanding

- Global attainment for your research

- Manuscript accessibility in different formats

( Pdf, E-pub, Full Text, Audio)

- Unceasing customer service

Track the below URL for one-step submission https://juniperpublishers.com/online-submission.php 